\title{
Accelerated Approval
}

National Cancer Institute

\section{Source}

National Cancer Institute. Accelerated Approval. NCI Thesaurus. Code C156638.

A regulatory process that allows for shortened time to approval of drugs that treat

serious conditions and/or fill an unmet medical need based on surrogate or intermediate clinical endpoints. 